\title{
Advances in Diagnosis of Respiratory Diseases of Small Ruminants
}

\author{
Sandip Chakraborty, ${ }^{1}$ Amit Kumar, ${ }^{2}$ Ruchi Tiwari, ${ }^{2}$ Anu Rahal, ${ }^{3}$ Yash Malik, \\ Kuldeep Dhama, ${ }^{5}$ Amar Pal, ${ }^{6}$ and Minakshi Prasad ${ }^{7}$ \\ ${ }^{1}$ Animal Resources Development Department, Pt. Nehru Complex, Agartala 799006, India \\ ${ }^{2}$ Department of Veterinary Microbiology, College of Veterinary Sciences and Animal Husbandry, \\ Uttar Pradesh Pandit Deen Dayal Upadhayay Pashu Chikitsa Vigyan Vishwa Vidyalaya Evam Go-Anusandhan Sansthan (DUVASU), \\ Mathura 281001, India \\ ${ }^{3}$ Division of Pharmacology and Toxicology, Indian Veterinary Research Institute, Izatnagar 243122, India \\ ${ }^{4}$ Division of Standardization, Indian Veterinary Research Institute, Izatnagar 243122, India \\ ${ }^{5}$ Division of Pathology, Indian Veterinary Research Institute, Izatnagar 243122, India \\ ${ }^{6}$ Division of Surgery, Indian Veterinary Research Institute, Izatnagar 243122, India \\ ${ }^{7}$ Department of Animal Biotechnology, College of Veterinary Sciences, Lala Lajpat Rai University of Veterinary and \\ Animal Sciences (LLRUVAS), Hisar 125004, India
}

Correspondence should be addressed to Anu Rahal; rahalanu72@gmail.com

Received 11 March 2014; Accepted 1 May 2014; Published 15 June 2014

Academic Editor: Praveen Malik

Copyright (C) 2014 Sandip Chakraborty et al. This is an open access article distributed under the Creative Commons Attribution License, which permits unrestricted use, distribution, and reproduction in any medium, provided the original work is properly cited.

\begin{abstract}
Irrespective of aetiology, infectious respiratory diseases of sheep and goats contribute to 5.6 percent of the total diseases of small ruminants. These infectious respiratory disorders are divided into two groups: the diseases of upper respiratory tract, namely, nasal myiasis and enzootic nasal tumors, and diseases of lower respiratory tract, namely, peste des petits ruminants (PPR), parainfluenza, Pasteurellosis, Ovine progressive pneumonia, mycoplasmosis, caprine arthritis encephalitis virus, caseous lymphadenitis, verminous pneumonia, and many others. Depending upon aetiology, many of them are acute and fatal in nature. Early, rapid, and specific diagnosis of such diseases holds great importance to reduce the losses. The advanced enzyme-linked immunosorbent assays (ELISAs) for the detection of antigen as well as antibodies directly from the samples and molecular diagnostic assays along with microsatellites comprehensively assist in diagnosis as well as treatment and epidemiological studies. The present review discusses the advancements made in the diagnosis of common infectious respiratory diseases of sheep and goats. It would update the knowledge and help in adapting and implementing appropriate, timely, and confirmatory diagnostic procedures. Moreover, it would assist in designing appropriate prevention protocols and devising suitable control strategies to overcome respiratory diseases and alleviate the economic losses.
\end{abstract}

\section{Introduction}

Small ruminants particularly sheep and goats contribute significantly to the economy of farmers in Mediterranean as well as African and Southeast Asian countries. These small ruminants are valuable assets because of their significant contribution to meat, milk, and wool production, and potential to replicate and grow rapidly. The great Indian leader and freedom fighter M. K. Gandhi "father of the nation" designated goats as "poor man's cow," emphasizing the importance of small ruminants in poor countries. In India, sheep and goats play a vital role in the economy of poor, deprived, backward classes, and landless labours. To make this small ruminant based economy viable and sustainable, development of techniques for early and accurate diagnosis holds prime importance. Respiratory diseases of small ruminants are multifactorial [1] and there are multiple etiological agents responsible for the respiratory disease complex. Out of them, bacterial diseases have drawn attention due to variable clinical manifestations, severity of diseases, and reemergence 
of strains resistant to a number of chemotherapeutic agents [2]. However, sheep and goat suffer from numerous viral diseases, namely, foot-and-mouth disease, bluetongue disease, maedi-visna, orf, Tick-borne encephalomyelitis, peste des petits ruminants, sheep pox, and goat pox, as well as bacterial diseases, namely, blackleg, foot rot, caprine pleuropneumonia, contagious bovine pleuropneumonia, Pasteurellosis, mycoplasmosis, streptococcal infections, chlamydiosis, haemophilosis, Johne's disease, listeriosis, and fleece rot [3$10]$.

The respiratory diseases represent 5.6 per cent of all these diseases in small ruminants [11]. Small ruminants are especially sensitive to respiratory infections, namely, viruses, bacteria, and fungi, mostly as a result of deficient management practices that make these animals more susceptible to infectious agents. The tendency of these animals to huddle and group rearing practices further predispose small ruminants to infectious and contagious diseases $[6,9]$. In both sheep and goat flocks, respiratory diseases may be encountered affecting individuals or groups, resulting in poor live weight gain and high rate of mortality [5]. This causes considerable financial losses to shepherds and goat keepers in the form of decreased meat, milk, and wool production along with reduced number of offspring. Adverse weather conditions leading to stress often contribute to onset and progression of such diseases. The condition becomes adverse when bacterial as well as viral infections are combined particularly under adverse weather conditions [1]. Moreover, under stress, immunocompromised, pregnant, lactating, and older animals easily fall prey to respiratory habitats, namely, Streptococcus pneumoniae, Mannheimia haemolytica, Bordetella parapertussis, Mycoplasma species, Arcanobacterium pyogenes, and Pasteurella species [2, 4, 7-9, 12, 13]. Such infections pose a major obstacle to the intensive rearing of sheep and goat and diseases like PPR, bluetongue, and ovine pulmonary adenomatosis (Jaagsiekte) adversely affect international trade $[2,9,10,13]$, ultimately hampering the economy.

\section{Respiratory Diseases of Small Ruminants}

Depending upon the involvement of etiological agent, the infectious respiratory diseases of small ruminants can be categorized as follows $[9,14]$ :

(1) bacterial: Pasteurellosis, Ovine progressive pneumonia, mycoplasmosis, enzootic pneumonia, and caseous lymphadenitis,

(2) viral: PPR, parainfluenza, caprine arthritis encephalitis virus, and bluetongue,

(3) fungal: fungal pneumonia,

(4) parasitic: nasal myiasis and verminous pneumonia,

(5) others: enzootic nasal tumors and ovine pulmonary adenomatosis (Jaagsiekte).

Manytimes due to environmental stress, immunosuppression, and deficient managemental practices, secondary invaders more severely affect the diseased individuals; moreover, mixed infections with multiple aetiology are also common phenomena $[5,8,13,15]$.

These conditions involve respiratory tract as primary target and lesions remain confined to either upper or lower respiratory tract $[7,16]$. Thus, these diseases can be grouped as follows $[5,8,14,17]$.

(1) Diseases of upper respiratory tract, namely, nasal myiasis and enzootic nasal tumors, mainly remain confined to sinus, nostrils, and nasal cavity. Various tumors like nasal polyps (adenopapillomas), squamous cell carcinomas, adenocarcinomas, lymphosarcomas, and adenomas are common in upper respiratory tracts of sheep and goats. However, the incidence rate is very low and only sporadic cases are reported.

(2) Diseases of lower respiratory tract, namely, PPR, parainfluenza, Pasteurellosis, Ovine progressive pneumonia, mycoplasmosis, caprine arthritis encephalitis virus, caseous lymphadenitis, verminous pneumonia, and many others which involve lungs and lesions, are observed in alveoli and bronchioles.

Depending upon the severity of the diseases and physical status of the infected animals, high morbidity and mortality can be recorded in animals of all age groups. These diseases alone or in combination with other associated conditions may have acute or chronic onset and are a significant cause of losses to the sheep industry $[3,10]$. Thus, the respiratory diseases can also be classified on the basis of onset and duration of disease as mentioned below $[3,9,14,18]$ :

(1) acute: bluetongue, PPR, Pasteurellosis, and parainfluenza,

(2) chronic: mycoplasmosis, verminous pneumonia, nasal myiasis, and enzootic nasal tumors,

(3) progressive: Ovine progressive pneumonia, caprine arthritis encephalitis virus, caseous lymphadenitis, and pulmonary adenomatosis.

\section{Need of Advanced Diagnostic Approaches}

The potential losses due to respiratory diseases can be minimized by sound diagnostic approach along with sound management programme [15]. Any kind of compromise with the diagnostic and management approach would severely affect the health status of the flock [19]. Early, rapid, and effective diagnosis of the respiratory diseases in small ruminants is a challenge due to limited laboratory resources in African and Southeast Asian countries where a large small ruminant population gets decimated due to respiratory disease outbreaks $[15,16]$. Conventional methods of diagnosis may be available more frequently but they usually take longer to yield results, and also their specificity and sensitivity may not be up to the mark. In recent past, many advanced, rapid, sensitive, and specific serological and molecular tests have been developed. These diagnostic methods have supplanted the conventional diagnostic procedures owing to their speed, 


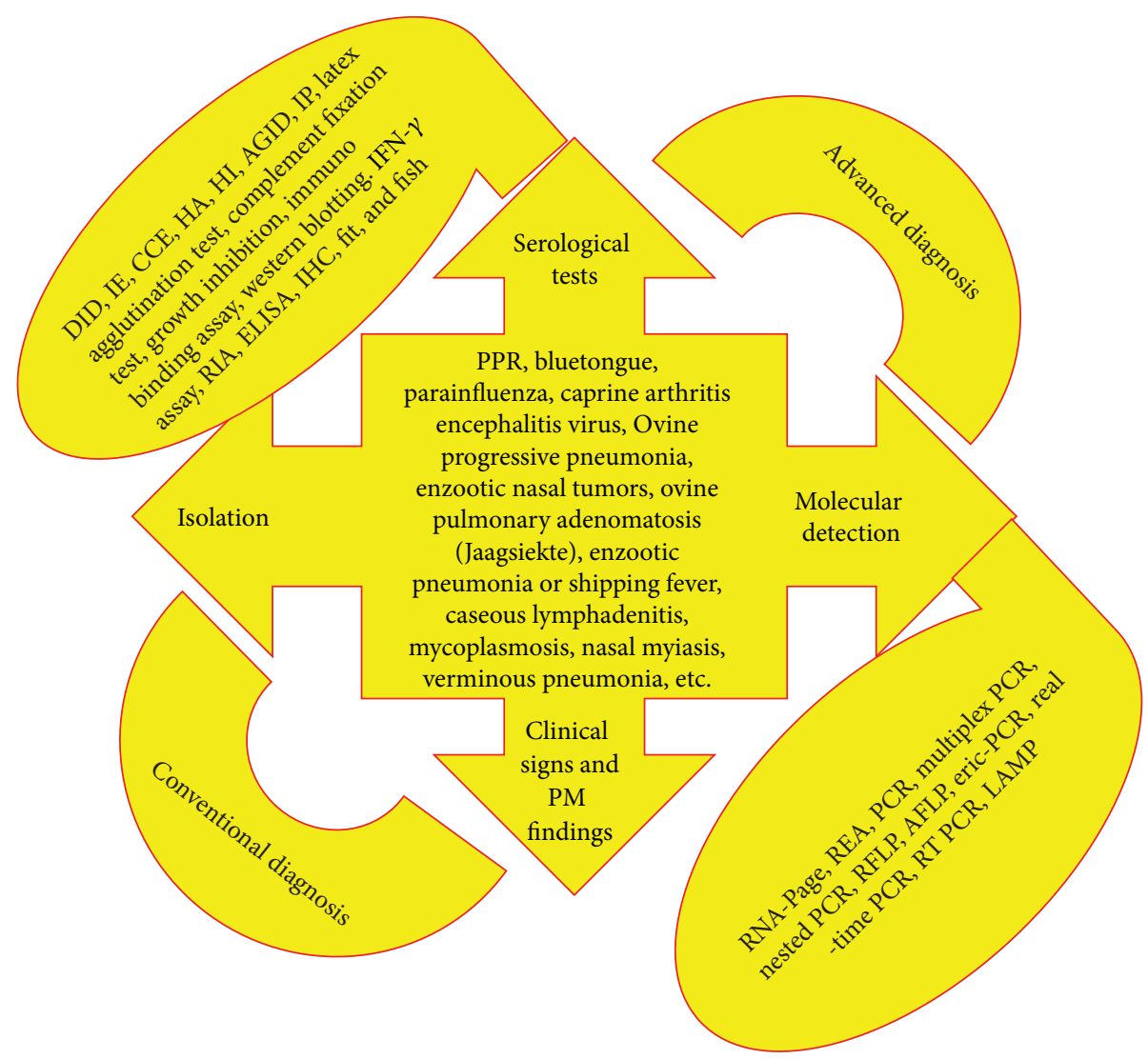

FIGURE 1: Diagnosis of infectious respiratory diseases of small ruminants.

sensitivity, specificity, and applicability even without isolation of etiological agent $[20,21]$.

In present scenario of globalization and regulations related to international trades, continuous monitoring of enlisted diseases is mandatory and for that sampling, isolation, and confirmation processes are very tedious [22, 23]. In such scenario, the rapid and specific detection of antibodies to the respiratory pathogens is now possible by the advancement in serological testing. Availability of better serological tests including ELISAs and monoclonal antibodies has enabled detection of antibodies to these infectious agents (namely, bacteria, viruses, and fungi) with more rapidity as well as specificity [24]. Moreover, due to advancement in the polymerase chain reaction (PCR) technology, there has been enormous improvement in the diagnosis of respiratory diseases of small ruminants [25]. Recent advances in biotechnology and molecular biology have led to the development of a variety of diagnostic assays, namely, PCR, RT-PCR, PCR-ELISA, RAPD, AFLP, RFLP, real-time PCR, quantitative PCR, multiplex PCR, LAMP, microsatellites, gene sequencing, and phylogenetic analysis, which not only help in identification but also assist in molecular characterization of various pathogens [20, 2237]. Various conventional diagnostic tests, namely, isolation, postmortem finding, and gross clinical examinations along with modernized serological and molecular tests, are enlisted in Figure 1.
Advances in diagnostic tools and assays help strengthening the surveillance and monitoring systems of animal diseases. The latest advances in molecular techniques have assisted in the rapid and confirmatory diagnosis of the diseases and epidemiological studies to formulate appropriate and timely prevention, treatment, and control measures, and alleviation of economic losses to animal producers $[1,7,13$, $22,23]$.

\section{Advances in Diagnosis of Respiratory Diseases of Small Ruminants}

For the prevention and control of fatal infectious respiratory diseases of small ruminants, various diagnostic strategies are adopted worldwide. The diagnostic tests as well as procedures adopted in different parts of world incorporate combination of conventional and advanced diagnostic tests. However, the initial suggestive diagnosis involves the observation of clinical signs and postmortem findings followed by serological and molecular methods for the confirmation of etiological agents. Common infectious respiratory diseases of small ruminants, clinical signs, postmortem findings, and diagnostic tests are compiled in Table 1.

4.1. Peste des Petits Ruminants (PPR). Peste des petits ruminants (PPR) is an acute and highly contagious viral disease of small ruminants and in particular of goats, popularly known 


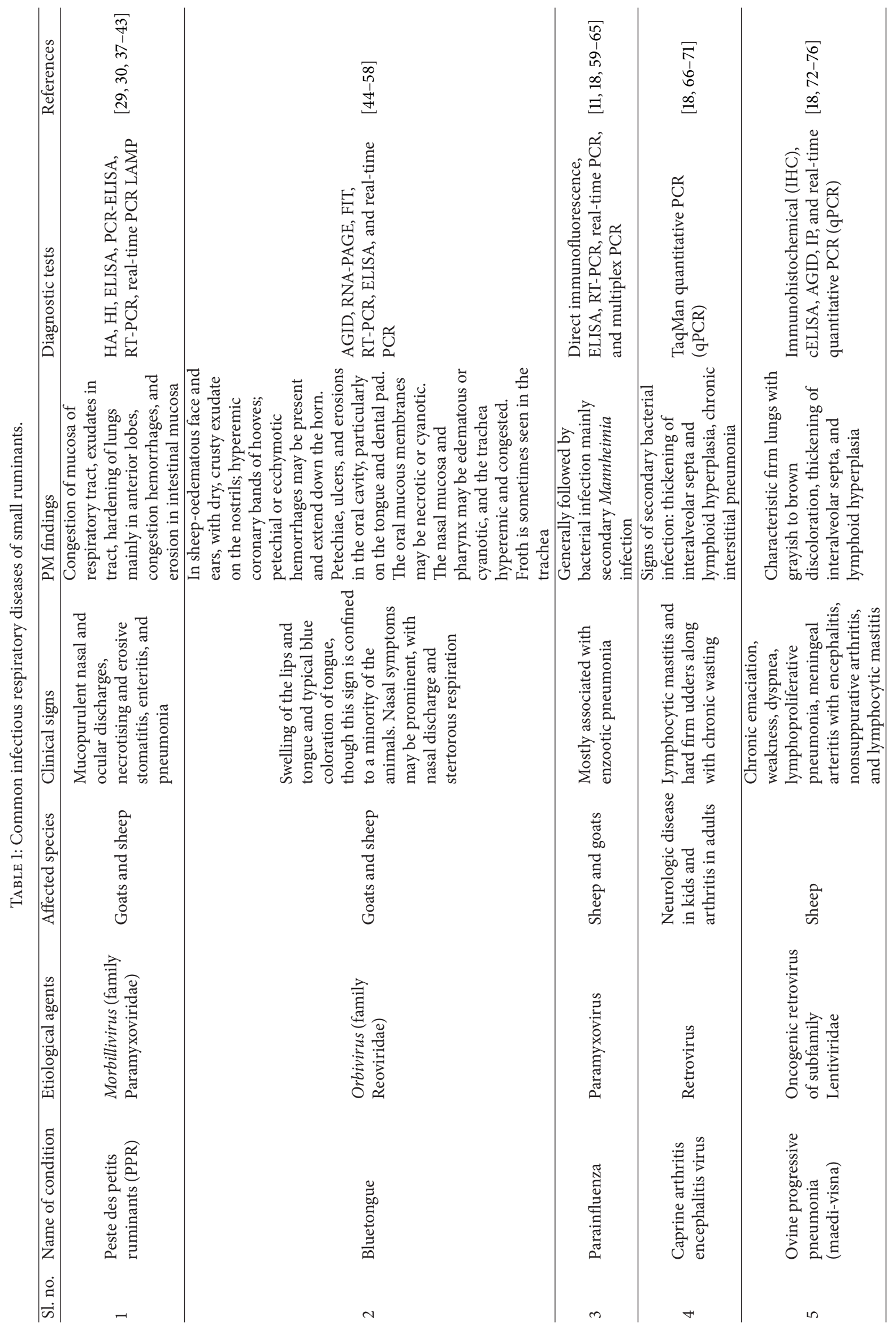




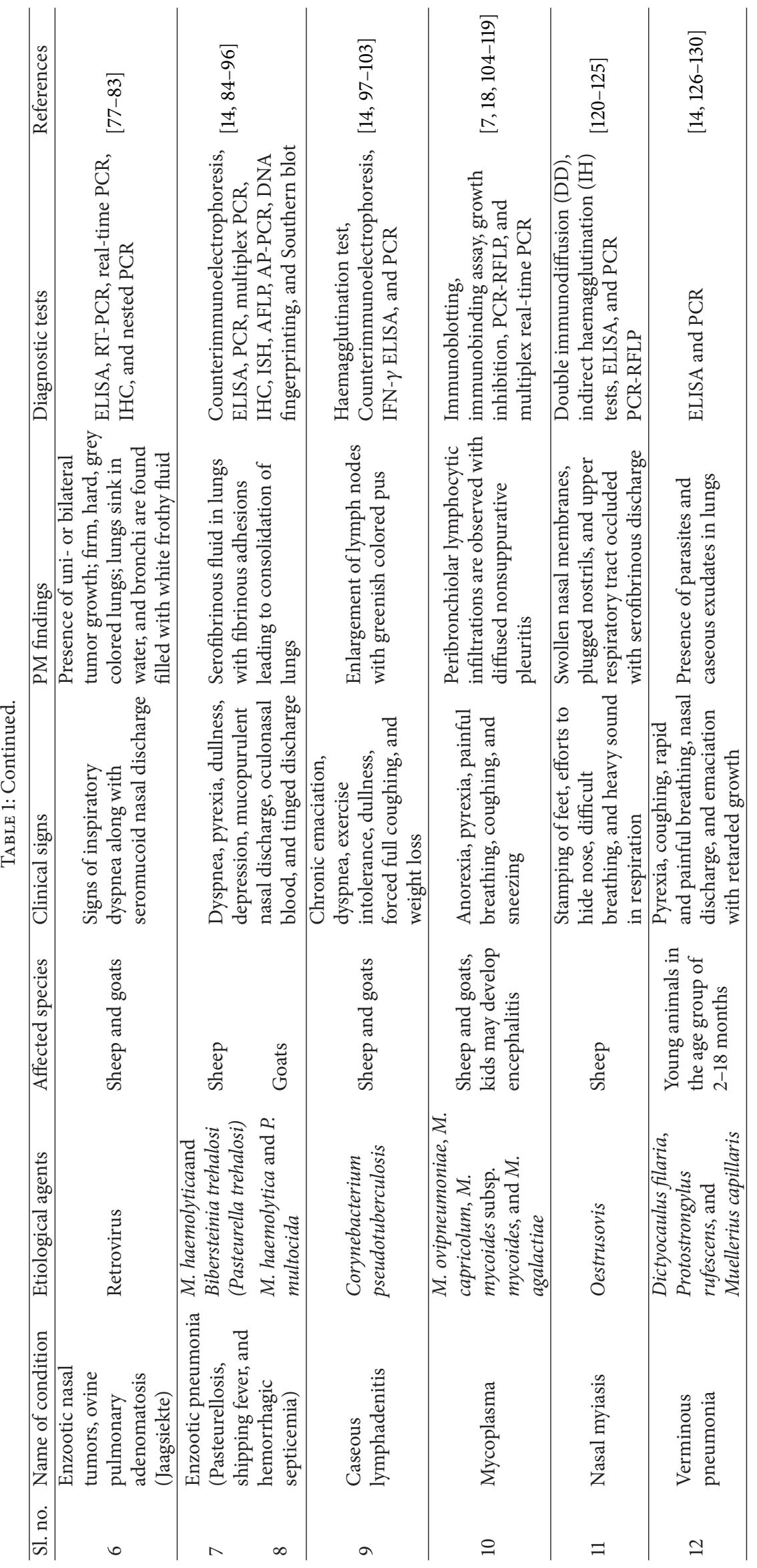


as goat plague $[38,39]$. Transmission of the disease takes place by direct contact with the secretions or excretions from the infected animals to healthy ones, which are in close contact. Clinically, PPR is characterized by pyrexia, ocular and nasal discharges, erosive stomatitis, and diarrhea [38, 40]. The postmortem findings are limited mainly to the alimentary tract that consists of erosive stomatitis (extensive in nature) as well as hemorrhagic gastroenteritis. Often, streaks of congestion may be found along the mucosal folds that result in the characteristic appearance of "zebra-strip" [131,132]. The morbidity and mortality rates of PPR can be as high as $100 \%$ and over $90 \%$, respectively $[39,40]$.

The various serological tests applied in the PPR detection include agar gel immunodiffusion, virus neutralization, complement fixation, haemagglutination inhibition, and competitive ELISA assays. Conventional serological tests like complement fixation or haemagglutination inhibition cannot differentiate between PPR and Rinderpest (RP). However, haemagglutination inhibition (HI) can be used quantitatively for the measurement of PPRV antibodies in suspension. Titration of the PPRV antigen can be done by the use of both haemagglutination (HA) and HI tests [39-41]. Peste des petits ruminant's virus (PPRV) can be differentiated from Rinderpest (RP) by virus neutralization and competitive ELISA assays. Competitive ELISA can be a better choice for detection of antibody to PPR because of its high specificity of diagnosis [40]. A rapid as well as sensitive and virus-specific test for detection of PPRV antigen is immunocapture ELISA that can cause differentiation of RP and PPR. It has got higher sensitivity than routinely used agar gel immunodiffusion test $[36,42,133]$.

There has been a substantial improvement in the techniques to detect the nucleic acids of PPRV. PCR assays are now considered as powerful as well as novel means of detection and quantification of the nucleic acids of PPR virus in various types of clinical samples. But unfortunately, no single assay can detect all the lineages of the virus. Companion tests can be developed by manipulation of the PPRV gene and insertion of either positive or negative markers $[25,29,30]$. The nucleoprotein based RT-PCR, which is based on nucleoprotein $(\mathrm{N})$ genes, has been standardized recently. Instead of analysis of the amplified product by means of agarose gel electrophoresis, its detection is done on a plate by ELISA using labeled probe. The sensitivity of this RTPCR ELISA is ten times higher than the classical RT-PCR. With the aid of quantitative real-time RT-PCR, there has been significant improvement in the diagnosis of PPR $[29,30]$. This minimizes the risk of contamination. There is also description of applying nucleic acid amplification for the diagnosis of PPR. The sensitivity of this assay is similar to that of PCR but its simplicity in implementation, as the results can be read by naked eye, and rapidity make it suitable for practical application $[32,34]$.

Use of LAMP significantly reduced the processing time of sample and final outcome [21]. Similarly, LAMP assay based on conserved region of "N" gene of PPR virus has been documented for rapid and specific detection of PPR virus from clinical samples. The assay was found 100-1000 times superior to PCR and s-ELISA [43].
Synthetic peptide and multiple antigenic peptide based antigen has been employed in ELISA for detection of PPR virus antibodies. A PCR-ELISA based on $\mathrm{N}$ gene has been standardized in order to detect PPR virus thereby yielding a product (which is labeled with digoxigenin) that comprises a sequence from $\mathrm{N}$ gene of the PPRV. The assay has been found to be more sensitive than sandwich ELISA in order to detect the virus in both early and late phases of the disease. For differential diagnosis of PPRV from Rinderpest virus, also the assay has been found to be useful [27]. A onestep multiplex RT-PCR (single tube) has been standardized for amplification of specific fragments of the $\mathrm{N}$ as well as $\mathrm{M}$ genes of PPR virus. For detection of the virus directly from clinical field samples, the RT-PCR is conducted by the use of purified viral RNA. The assay is easier than the two-step assay as it is time saving requiring only one buffer for both reverse transcription and PCR [29]. RT-PCR based on $\mathrm{F}$ gene has shown a low sensitivity as well as specificity along with moderate agreement as compared to sandwich ELISA [36]. By the use of one-step Brilliant SYBR Green Kit, a sensitive as well as rapid single step real-time RT-PCR has been standardized for detection and semiquantitation of PPRV by the use of primers specific to viral RNA and matrix protein gene. They have been compared with conventional RT-PCR as well as Taqman RT-PCR. It has been found that the assay is more rapid as well as sensitive than TaqMan and the conventional RT-PCR in order to detect nucleic acid of PPRV from the clinical samples of sheep as well as goat, which are suspected for PPR. As an alternative test to the various diagnostic assays that already exist, SYBR Green RT-PCR has been found to be a successful tool thereby helping in rapid clinical diagnosis with advantage of reducing contamination risk $[30,37]$.

4.2. Bluetongue. Bluetongue (BT) is one of the important infectious diseases of domestic and wild ruminants. It is caused by bluetongue virus (BTV) of genus Orbivirus and family Reoviridae. The disease, transmitted by Culicoides (biting midges), was first reported in India in 1964 [134]. India has significant populations of domestic and wild ruminants, which are known to be susceptible to BTV infection. Several exotic breeds of sheep were introduced into the country between 1960 and 1970 for genetic improvement of the national flock by crossbreeding with native breeds [135]. This increase in the susceptible population, along with favorable climatic conditions, appears to have led to the establishment of BTV in the country $[135,136]$. The disease has an incubation period of 5-20 days with the development of symptoms within a month. There is low mortality rate but in susceptible breeds of sheep the mortality may be high [136]. Asymptomatic infection is usually observed in cattle as well as goats and wild ruminants despite the high level of virus in the blood. Exception is red deer in which the disease may be as acute as in sheep [137]. The development in diagnostic technologies has confirmed over the past that BTV is now widely spread in several parts of India $[136,138]$.

Traditionally, the diagnosis of BTV is primarily based on clinical signs and symptoms. However, differential diagnosis 
with some of the diseases such as contagious ecthyma, foot and mouth disease (FMD), vesicular stomatitis, malignant catarrhal fever (MCF), bovine virus diarrhea (BVD), infectious bovine rhinotracheitis (IBR), parainfluenza-3 infection, and sheep pox should be done $[135,136,139]$. The confirmatory diagnosis may be done either through virus isolation or through serological test. The virus isolation is performed in embryonated chicken eggs, in cell culture (BHK-21 or Vero cell line), or occasionally in sheep [139]. The virus is serotyped either by virus neutralization tests such as plaque reduction, plaque inhibition, Microtiter neutralization, and Fluorescence inhibition test (FIT) or through reverse-transcription polymerase chain reaction (RT-PCR) (a prescribed test for international trade) [50,51]. A highly sensitive silver staining method of RNA-polyacrylamide gel electrophoresis (RNAPAGE) of bluetongue virus was developed recently [49]. Various serological tests such as complement fixation test (now largely replaced by the AGID test), agar gel immunodiffusion, and competitive enzyme-linked immunosorbent assay (both are prescribed test for international trade) are used for serological characterization of BTV. Recently, novel Indian isolates of BTV 21 were detected employing real-time PCR assay [44]. The complete genome sequence of BTV serotype 16 of goat origin from India has also been carried out [140]. Similarly, the complete genome sequences of BTV22 and reassortment strain of BTV 2, 3, 16, and 23 from India have been carried out recently $[45-48,52]$. Analyses of the nucleotide sequence as well as phylogenetic comparisons of genome segment 2 that encodes outer-capsid protein VP2 help in creation of segment-2 database [53]. Such database is used for developing rapid as well as reliable typing assay based on RT-PCR [50,51, 54]. Testing of multiple primer pairs has also been done that provides an identification of serotype initially by amplifying a cDNA product of the expected size. Confirmation of serotype has been done by sequencing of the cDNA amplicons and subsequently phylogenetic analysis is done for comparing with reference strains that are previously characterized $[52,54]$. The RT-PCR assay provides a rapid as well as sensitive and reliable method to identify and differentiate all the serotypes of BTV [45, 50, 51, 55-58].

4.3. Parainfluenza. Parainfluenza is mainly characterized at necropsy by purulent bronchopneumonia (focal) along with moderate to severe pulmonary congestion. Histopathological analysis has revealed the presence of acute and severe as well as diffuse necrotizing and fibrinous or suppurative bronchopneumonia. There is also a presence of diffuse congestion as well as pulmonary edema [61]. As a diagnostic method, comparison of enzyme immunoassay has been done with complement fixation test (CFT). The cross-reactivity of the viruses can be detected by the application of such tests [59]. Parainfluenza is a viral infection of the lower respiratory tract causing an enormous burden of disease in small ruminants. Direct immunofluorescence technique along with cross-neutralization tests is required for antigenic analysis of the parainfluenza virus isolates. For detection of the virus associated with it, new diagnostic test like multiplex PCR has got enormous advantages mainly because of its specificity [17]. Real-time PCR (RT-PCR) is a useful molecular tool for detection of parainfluenza virus type 3 (Pi3) from ribonucleic acid (RNA) samples from cells of the lungs from the slaughtered animals. This is followed by sequencing as well as restriction enzyme patterns of the fragment amplified of the F gene which confers confirmation of the distinctness of the isolates. Availability of suitable PCR primers allows detection of the ovine virus specifically [62]. Phylogenetic analysis of the amino acid as well as the nucleotide sequences is also equally important [60]. In some of the instances, it has been seen that the inhouse RT-PCR methods cannot yield expected products for which the nucleotide sequence analysis has been initiated [63]. Multiplex RT-PCR can help distinguish parainfluenza viruses from other respiratory virus like adenovirus [64]. Nucleic acid sequence based amplification (NASBA) has been developed for which primers as well as probes have been selected from the haemagglutinin-neuraminidase $(\mathrm{HN})$ gene as well as from the phosphoprotein $(\mathrm{P})$ of the parainfluenza virus $[61,65]$.

4.4. Caprine Arthritis Encephalitis Virus. Caprine arthritis encephalitis virus (CAEV) is a member of the lentivirus family (in small ruminants) leading to chronic disease of the joints and rarely encephalitis in goat kids under the age of six months. The virus is in close intimation with white blood cells. Thus, any kinds of body secretions containing blood cells are potential sources for virus spread to other animals in the herd [141, 142]. In goats, in order to detect caprine arthritis encephalitis virus (CAEV), serological tests or cell cultures are mainly used. Besides, PCR has also been developed for detection of CAEV sequences from peripheral blood mononuclear cells (PBMC), synovial fluid cells (SFC), and milk cells (MC) from the infected goats. This type of PCR assay especially provides a useful method to detect CAEV infection in goats [66-68]. A two-step TaqMan quantitative (q) PCR, which is specific as well as sensitive for the detection of infection due to CAEV by the use of a set of primers (specific), and a TaqMan probe that targets a region which is highly conserved within the gene that encodes the capsid protein of the virus have been developed [33]. In the total deoxyribonucleotide (DNA) extracts, the proviral DNA can be detected successfully by this assay. The TaqMan qPCR assay provides a fast as well as specific and sensitive means for detection of proviral DNA of the virus and thereby proves to be useful for detection in large scale for eradication programs as well as epidemiological studies.

PCR techniques have been standardizedin several laboratories for the detection of proviral DNA. Other molecular techniques such as cloning and sequencing are also used to provide knowledge on a country or region's specific strain of CAEV. Phylogenetic analyses of the proviral DNAs of CAEV throughout the world have given the suggestion that in certain areas CAEV causes natural infection not only in goats but also in sheep. In order to track the transmission of the disease in near future, phylogenetic analyses may be used [66, $69,70]$. Molecular techniques such as cloning and sequencing are also used to provide knowledge on the prevalence of 
specific strain of CAEV in a country or a region which may have influence on serological assay as well as corresponding CAEV antigen $[33,71]$.

4.5. Ovine Progressive Pneumonia (Maedi-Visna). Most of the sheep suffering from Ovine progressive pneumonia (OPP) do not show the clinical signs until the age of 2 years due to the long incubation period of the virus. General loss in body condition known as the "thin ewe syndrome" is the first sign of the disease. There may be loss of weight in spite of the normal appetite of the affected sheep [143, 144]. Several serological tests like agar gel immunodiffusion (AGID), immunoprecipitation (IP), and competitive ELISA (cELISA) are used for the diagnosis of Ovine progressive pneumonia with the use of methionine-labelled antigen A [73]. Real-time quantitative PCR (qPCR) which is specific for the transmembrane region of the envelope gene (tm) has been compared with competitive inhibition enzymelinked immunosorbent assay (cELISA) using sheep sera. The qPCR assay indicates excellent agreement between the two tests. Both disrupted whole virus and recombinant viral proteins have been utilized in indirect ELISAs which have shown high sensitivity as well as specificity of detection [73]. Such experiments have proved that the proviral loads of Ovine progressive pneumonia virus (OPPV) qPCR can be confirmed by cloning as well as sequencing and can be used as diagnostic tool for OPPV infection as well as measurement of viral load in sheep which are infected $[74,75]$. Single enzymebased automated immunohistochemical (IHC) analysis has been developed to detect capsid antigen (CA) of OPPV that uses two anti-CAEV monoclonal antibodies, namely, 5A1 as well as 10A1 along with two enzyme-based IHC systems. The CA of OPPV has been detected in the intracellular regions of the synovial membrane of the carpus, in the cells that resemble alveolar macrophages as well as interstitial macrophages in the lung tissue, and so also in alveolar cells of the mammary gland [76]. Comparison of a new real-time quantitative PCR (qPCR) which is specific for the envelope gene's transmembrane region has been done with a competitive ELISA (cELISA). Such comparative test has led to the conclusion that qPCR may be used as a supplemental tool for diagnosis and for measuring the load of the virus [71, 145].

\subsection{Enzootic Nasal Tumors and Ovine Pulmonary Adeno-} matosis (Jaagsiekte). From the diagnostic point of view of enzootic nasal tumors and ovine pulmonary adenomatosis, it is important to note that the genome of the ovine pulmonary adenomatosis virus is 7,434 nucleotides long thereby exhibiting a genetic organization of type $B$ as well as $D$ oncoviruses. The enzootic nasal tumor virus is closely related to the Jaagsiekte retrovirus of sheep as well as to sheep endogenous retroviruses [146, 147]. Diagnosis of enzootic nasal tumors is based on mainly clinical findings. Endoscopy reveals occlusion in the caudal part of one or both the nasal cavities. Radiography may also reveal the extent of the lesion. Provisional diagnosis can be made by the biopsy of the mass during the period of endoscopic examination [80]. RT-PCR for the diagnosis of Jaagsiekte is very important in order to formulate prevention as well as control strategies. The envelope (env) gene is mainly targeted for this purpose [81]. For development of an assay based on serology, identification of three proteins has been done as candidate diagnostic antigens, namely, Jaagsiekte sheep retrovirus (JSRV) p26 (which is a group specific antigen), the transmembrane, and the open reading frame (ORF)-X proteins. Isolation of the genes coding for all the three proteins has been done followed by cloning as well as expression. Purification of the JSRV p26 has been done as a potential diagnostic antigen by both Western blot and ELISA. Investigation of three molecular assays has been done for their sensitivity as well as specificity: the long terminal repeat (LTR) group specific antigen (gag) PCR, LTR heminested PCR, and the PCR covering the V1 or $\mathrm{V} 2$ region. The use of AmpliTaq gold DNA polymerase increases the specificity of heminested PCR. The complete genome sequence of the ovine enzootic nasal tumor virus has been done which has shown its exclusive association with contagious intranasal tumors of sheep $[79,82,83]$.

4.7. Enzootic Pneumonia or Shipping Fever. Before discussing enzootic pneumonia in sheep, it has to be kept in mind that as far as the transmission of the disease from diseased to healthy animals is concerned, no direct evidence is available yet. As per suggestion, it has been noted that there may be precipitation of outbreaks due to abrupt environmental changes and it may also be associated with a sharp change in weather conditions $[86,87]$. Such infection in animals caused by a bacterial species related to genus Pasteurella is known as Pasteurellosis. After the taxonomic revision in 1999, the species is classified as Mannheimia species. Pasteurella multocida ( $P$. septica) is carried in mouth and respiratory tract of several animals, notably cats. The organisms are small Gram-negative bacillus with bipolar staining. P. multocida, a common commensal, causes numerous pathological conditions in domestic animals, avian species, and human beings. Pasteurellosis is associated with a close animal contact and may be transmitted by animal bite [88, 89]. Severe clinical conditions occur when the organism is associated with other infectious agents, such as mycoplasma, chlamydia, and viruses [7, 9]. Environmental conditions and various stress factors such as transportation, housing deficiency, and bad weather also play a role to further aggravate the clinical conditions. Among the various diseases considered to be caused by $P$. multocida, alone or in association with other pathogens, most important is shipping fever in cattle and sheep, which may also be caused by Mannheimia haemolytica, in the absence of $P$. multocida. Fresh samples are the prerequisites for isolation of Pasteurella multocida and subsequently demonstration of the bipolar staining characteristic. A wide range of media that can be used for isolation of the organism are blood and chocolate agar and casein/sucrose/yeast (CSY) agar with supplementation of $5 \%$ blood. Other media include dextrose starch agar as well as trypticase soy agar. For demonstration of the characteristic staining feature, methylene blue or Leishman's stain is usually used. For serotyping, the tests include rapid slide agglutination test as well as indirect haemagglutination 
test (for capsular typing); for somatic typing an agglutination test; and agar gel immunodiffusion for both capsular and somatic typing. For the rapid identification of capsular type, counterimmunoelectrophoresis is an important diagnostic tool. Dot immunobinding assay, immunoblotting of outer membrane proteins of vaccine, and field isolates of Pasteurella multocida have been used for rapid diagnosis [90, 91]. Comparative analysis of the outer membrane protein profiles of haemorrhagic septicaemia associated $P$. multocida by immunoblotting studies indicated that the major OMP of P. multocida (B: 2) is highly antigenic and $37 \mathrm{kDa}$ OMP has potential for protective and immunodiagnostic studies [92].

In clinical samples as well as bacterial cultures, detection of organisms can be done by PCR. The pair of primers for this particular assay can amplify a 353 base pair (bp) fragment of the 16srRNA gene, which ultimately results in the amplification of DNA. Thus, this kind of PCR assay usually represents a valuable tool for diagnosing the disease early ultimately facilitating better control of the disease. Similar strategies can be adopted for the identification and confirmation of enzootic pneumonia in sheep with advanced molecular methods [20,35].

For epidemiological investigations, characterization of isolates can be done by DNA fingerprinting but availability of such diagnostic test is restricted to research laboratories [85, 93]. Southern hybridization can lead to confirmation of the presence of the bacterial sequence, which is often suggestive of the virulence of the organism [94]. Upon presumptive or definitive diagnosis, further differentiation of isolates can be achieved by genotypic fingerprinting methods. Restriction endonuclease analysis for characterization of serotypes of hemorrhagic septicaemia can be done with the enzyme HhaI. Discrimination of the isolates can be done by application of ribotyping as well as large DNA separation by means of pulsed-field gel electrophoresis. The rapidity as well as reproducibility of AFLP is high with higher index of discrimination. PCR fingerprinting is feasible in any laboratory, which has got the PCR capability. RAPD analysis as well as arbitrarily primed PCR (AP-PCR) is found to be useful for epidemiological investigation. For discriminating sheep as well as goat isolates, repetitive sequence PCR is also found to be useful. Repetitive extragenic palindromic REP-PCR as well as single prime PCR has been found to be useful for differentiating various serogroups of the bacteria $[95,96]$.

4.8. Caseous Lymphadenitis. The disease is caused by Corynebacterium pseudotuberculosis. There are two basic forms of caseous lymphadenitis, that is, internal form and external form. Most of the affected animals manifest both forms of the disease depending on the multiple factors that are age, physiological conditions, environmental factors, and managemental practices [148]. There is obvious nodule formation under the skin as well as enlargement of peripheral lymph nodes in the external form. The affected lymph nodes along with the subcutaneous tissues are enlarged with thick as well as cheesy pus which may rupture outward spontaneously or during the process of shearing or dipping. The internal form of caseous lymphadenitis (CLA) is manifested by vague signs such as weight loss, poor productivity, and decrease in fertility $[3,148,149]$. For the detection of the causative agent, Corynebacterium pseudotuberculosis, in sheep and goats, a double antibody sandwich ELISA has been developed, which has been further modified for improving the sensitivity. The main objective of developing this test is to detect the presence of antibodies against the bacterial exotoxin. It has been found that six proteins with varying molecular mass ranging from 29 to 68 kilo Dalton $(\mathrm{kDa})$ react with sera from both goats and sheep acquiring infection experimentally or naturally. For classification of the sera with inconclusive results, immunoblot analysis has been found to be valuable $[100,101]$. Quantification of interferon gamma (IFN- $\gamma$ ) is essential for accurate diagnosis of the disease for which an ovine IFN- $\gamma$ ELISA has been developed. The sensitivity of the assay is slightly more for sheep than in goats while the specificity of the assay is higher for goats than for sheep. It can thus be concluded that IFN- $\gamma$ is a potential marker in order to determine the status of CLA infection in small ruminants [102]. For the diagnosis of CLA, another novel strategy is the employment of PCR for identification of the bacteria isolated from abscesses [103]. The PCR has been found to be both sensitive and specific in addition to its rapidity of detecting $C$. pseudotuberculosis from sheep that are naturally infected [99].

4.9. Mycoplasmosis. As far as the antigenic variation is concerned, mycoplasmas have complex mechanisms enabling them to evade the immune system. They thereby cause several clinical symptoms which are having significant economic effect on production of small ruminants [107]. There are many species in genus Mycoplasma associated with pneumonic and respiratory conditions in small ruminants, namely, Mycoplasma agalactiae, Mycoplasma mycoides subspecies mycoides, Mycoplasma bovis, Mycoplasma capri, Mycoplasma capripneumoniae, Mycoplasma capricolum, Mycoplasma putrefaciens, and many others [7, 9, 104, 106-108]. Mycoplasmainfection associated syndromes range from septicemia (acute) along with death to chronicity of infection that results in reduced production [150]. Pneumonia accompanied by mastitis, keratoconjunctivitis, abortions, and arthritis is commonly observed in mycoplasma syndrome $[7,9,151]$. The conventional methods for diagnosis of mycoplasmosis include isolation of caprine and ovine mycoplasma in modified Hank's Balanced Salt Solution Liquid Media (MBHS-L), followed by biochemical characterization and staining [7, 9, 105]. Initially, serological tests like growth inhibition, agar gel immunodiffusion, counter current electrophoresis, complement fixation, PAGE, and others were performed [110]. However, cross-reactivity of closely related species could not be differentiated by these serological tests $[7-9,104]$. Immunobinding assay with polyclonal sera was able to differentiate closely related species [111]. It was followed by preparation of different antigens and purification with PAGE and SDS-PAGE in an attempt to identify potent specific immunogenic proteins of diagnostic values [112, 113]. Moreover, detection of protective and cross-reactive proteins with SDS-PAGE and immunoblotting showed some 
glimpse of diagnostic value $[9,114,115,151]$. These proteins provided base for selective and specific tests. Development of monoclonal antibodies based on such purified and specific immunogenic proteins led to development of very sensitive and specific sandwich ELISA based on monoclonal antibodies [116]. Molecular detection of Mycoplasma species based on different set of primers was used to identify different species [26]. For the development of monoclonal antibody based serological as well as ELISA-PCR, identification of species specific non-cross-reactive immunogenic proteins is mandatory, and for that proteins separated in SDS-PAGE were subjected to western blotting with homo- and heterologous sera against Mycoplasma agalactiae and Mycoplasma bovis [9, $114,115,151]$. These species specific immunogenic proteins can form the basis for development of many advanced diagnostic procedures for the detection of mycoplasma and its species confirmation.

Nowadays, for the molecular diagnosis of several clusters as well as groups, species specific primers along with restriction enzymes are used for confirmation of the agent by PCR as well as PCR-RFLP [107]. Still the combination of conventional and recently developed molecular methods is recommended for the identification and confirmation of contagious caprine pleuropneumonia (CCPP) in field outbreak [117]. For this purpose, growth inhibition test has been employed for identification of the agent followed by PCR. These two tests in particular detect two species of Mycoplasma, namely, Mycoplasma capricolum and Mycoplasma putrefaciens from nasal swab and lung cultures [118]. A multiplex real-time PCR has been developed for differentiation of the various Mycoplasma species of sheep and goat including Mycoplasma agalactiae. This assay particularly targets the two specific housekeeping genes, namely, polC and fusA considering which specific diagnostic primers and probes are to be developed $[105,106]$. It is however important to note that the assay requires further assessment of clinical specimens but for diagnosis on large scale basis the assay is very promising [119]. Primers specific to Mycoplasma conjunctivae (that causes pink eye in sheep and goat) have been used for amplification of a 750-base-pair fragment of the genome through PCR, which has been subsequently confirmed by agarose gel electrophoresis [107, 109].

4.10. Nasal Myiasis. Both double immunodiffusion (DD) and indirect haemagglutination $(\mathrm{IH})$ tests are used for detection of the somatic crude antigen first (L1) as well as second (L2) and third (L3) in star of the larva of the parasite Oestrus ovis [122]. For postmortem examination, sagittal sectioning of the head of the sheep suspected of suffering from nasal myiasis is carried out for detecting the presence of maggots or larvae [152]. It has been observed that there is no development of cross-immune reaction in sheep, which are naturally parasitized with all the three larval stages (as detected by DD test) and with L2 larvae (as detected by IH test) [124]. It is important to note that rhinoscopy examination can confirm the diagnosis and is equally important in treating the patient by removing the maggots with forceps [123]. For detection of seropositivity, ELISA is employed using a crude L2 larva as antigen [121]. Development of a direct ELISA by the use of a crude somatic antigen was developed from the first stage larva (L1). Validation of such system has been done with sera from both endemic and nonendemic areas [125]. The sensitivity as well as the specificity of the assay has been found to be high by the use of a cut-off point. PCR as well as automated sequencing technologies have been developed for molecular diagnosis of the disease [128]. PCR-RFLP has been used widely for identifying taxa of the parasite which are closely related and have forensic relevance [120]. It is also important to note that a better understanding of several target genes like mitochondrial DNA (mt DNA) as well as ribosomal DNA (rDNA) is pertinent for understanding the evolution of the parasite and so also for characterization of the proteins of the parasites $[120,123]$.

4.11. Verminous Pneumonia. In goats Muellerius capillaris is the most common lung worm. There is diffused pneumonia in affected goats without the presence of any nodular lesion. The parasite predisposes animals to secondary infections thereby compromising with the health in general [129]. A rapid as well as inexpensive method for assessment of herd exposure to lung worm in cattle is the bulk milk ELISA. It is a useful tool for the veterinary practitioners as a herd health monitoring programme component or in the perspective of investigation of herd health [126]. Over the past 15 years, studies have been conducted to prove that sequences of the internal transcribed spacers of ribosomal DNA provide useful genetic markers. This makes the basis for the molecular diagnosis of parasitic pneumonia in sheep and goat using PCR [130]. DNA probes as well as assays based on PCR are used for identification and detection of Dictyocaulus as well as Protostrongylus. The sensitivity of most of the PCRbased assays is more than DNA probe assays. Multiple steps are required for the development of assays based on PCR, which follows the selection of oligonucleotide primers at the initial stage along with reporter probe. It has been found that usually PCR detects the parasitic DNA but certainly advances have been made in preparing samples. For this purpose, it is required to extract the DNA while removing the PCR inhibitors. This helps in achieving greater sensitivity [128].

\section{Other Unusual Complications of Respiratory Tracts}

The respiratory diseases of small ruminants are generally fatal to lambs and kids. The lamb and kid pneumonia are mostly regarded as a complex of disease. It involves interaction of host related factors (immunological and physiological) and etiological agents, namely, virus, bacteria, mycoplasma, and environmental factors $[4,7,108]$. Many times, immunosuppression, malnutrition, and adverse climatic conditions lead to infection due to unusual infectious agents. There are reports on Streptococcus pneumoniae, commensal bacteria of the nasopharynx of animals associated with a majority of cases of morbidity and mortality in young lambs due to pneumonia $[7,13,153]$. Similarly, many other unusual 
pathogens Haemophilus ovis [154], Streptococcus spp., Pasteurella spp. [5, 6], M. bovis in sheep [7, 12] and goat [155], Mycoplasma arginini [12], and Haemophilus somnus [156] may cause pneumonia. Many time mixed infections are observed. Thus, isolation and identification of such samples are always tedious to perform $[7,9]$. The use of monoclonal antibodies based serological tests has simplified the process of early and specific diagnosis of many of these pathogens [24]. Simultaneously, development of molecular techniques like PCR particularly multiplex PCR is very useful for the identification and differentiation of etiological agents from such complex conditions [21].

\section{Conclusion and Future Perspectives}

For effective control of respiratory diseases of sheep and goat, accurate diagnosis along with genetic characterization of the causative agents is essential. It is especially important in present context of increased antibiotic and anthelmintic resistance. The known limitations of the traditional diagnostic techniques have created urgency to give a boost to the development of molecular diagnostic techniques along with establishment of traditional serodiagnostic facilities for overall progress in the field of respiratory disease diagnosis. Advancement in development and standardization of various kinds of PCR techniques along with genetic characterization of the causative agent has provided a solid foundation to develop practical as well as highly sensitive and specific diagnostic tools to help conduct epidemiological investigation and devise control programmes. Multiplexing of PCR assays has decreased confusion of diagnosticians in case of mixed infection as such assays can certainly differentiate between the various species within the same genera of pathogenic organism. It is obvious that advancement in the field of bionomics and biotechnology has led to the rapid and accurate diagnosis of many of these economically important diseases. All such efforts ultimately will lead to improvement of economic status of stakeholders of small ruminant husbandry and their sustainability. Development in field of nanotechnology has led to evolution of nanomedicine with the aid of which it will be certainly possible in near future to make further progress in the diagnosis and management of the respiratory diseases of small ruminants including wild life.

\section{Conflict of Interests}

The authors declare that there is no conflict of interests in the publication of this paper.

\section{References}

[1] D. Lacasta, L. M. Ferrer, J. J. Ramos, J. M. González, and M. De las Heras, "Influence of climatic factors on the development of Pneumonia in lambs," Small Ruminant Research, vol. 80, no. 1-3, pp. 28-32, 2008.

[2] M. Woldemeskel, M. Tibbo, and L. N. D. Potgieter, "Ovine progressive pneumonia (Maedi-Visna): an emerging respiratory disease of sheep in Ethiopia," Deutsche Tierarztliche Wochenschrift, vol. 109, no. 11, pp. 486-488, 2002.

[3] D. G. Pugh, Sheep and Goat Medicine, Saunders, Philadelphia, Pa, USA, 2002.

[4] K. A. Brogden, H. D. Lehmkuhl, and R. C. Cutlip, "Pasteurella haemolytica complicated respiratory infections in sheep and goats," Veterinary Research, vol. 29, no. 3-4, pp. 233-254, 1998.

[5] R. Kumar, R. C. Katoch, and P. Dhar, "Bacteriological studies on pneumonic gaddi sheep of Himachal Pradesh," Indian Veterinary Journal, vol. 77, no. 10, pp. 846-848, 2000.

[6] S. S. Soni and K. N. Sharma, "Descendence of natural bacterial flora as causative agent of pneumonia in sheep," Indian Journal of Comparative Microbiology Immunology and Infectious Diseases, vol. 11, pp. 79-84, 1990.

[7] A. Kumar, A. K. Verma, N. K. Gangwar, and A. Rahal, "Isolation, characterization and antibiogram of Mycoplasma bovis in sheep Pneumonia," Asian Journal of Animal and Veterinary Advances, vol. 7, no. 2, pp. 149-157, 2012.

[8] A. Kumar, A. K. Verma, A. K. Sharma, and R. Rahal, "Isolation and antibiotic sensitivity of Streptococcus pneumoniae infections with involvement of multiple organs in lambs," Pakistan Journal of Biological Sciences, vol. 16, no. 24, pp. 2021-2025, 2013.

[9] A. Kumar, A. Rahal, S. Chakraborty, A. K. Verma, and K. Dhama, "Mycoplasma agalactiae, an etiological agent of contagious agalactia in small ruminants-a Review," Veterinary Medicine InternationalIn Press, 2014.

[10] S. Chakraborty, N. Kumar, K. Dhama et al., "Foot-andmouth disease, an economically important disease of animals," Advances in Animal and Veterinary Sciences, vol. 2, supplement 2, pp. 1-18, 2014.

[11] J. C. Hindson and A. C. Winter, "Respiratory disease," in Manual of Sheep Diseases, pp. 196-209, Blackwell Science, Oxford, UK, 2nd edition, 2002.

[12] H. Bocklisch, V. Zepezauer, H. Pfützner, and S. Kreusel, "Demonstration of Mycoplasma in sheep pneumonia and experimental pneumonia produced by Mycoplasma arginini," Archiv fur experimentelle Veterinarmedizin, vol. 41, no. 2, pp. 249-257, 1987.

[13] L. Garedew, G. Ayelet, R. Yilma, A. Zeleke, and E. Gelaye, "Isolation of diverse bacterial species associated with maedi-visna infection of sheep in Ethiopia," African Journal of Microbiology Research, vol. 4, no. 1, pp. 14-21, 2010.

[14] S. Bell, "Respiratory disease in sheep 2. Treatment and control," In Practice, vol. 30, no. 5, pp. 278-283, 2008.

[15] P. R. Scott, "Treatment and control of respiratory disease in sheep," Veterinary Clinics of North America-Food Animal Practice, vol. 27, no. 1, pp. 175-186, 2011.

[16] J. A. Daniel, J. E. Held, D. G. Brake, D. M. Wulf, and W. B. Epperson, "Evaluation of the prevalence and onset of lung lesions and their impact on growth of lambs," American Journal of Veterinary Research, vol. 67, no. 5, pp. 890-894, 2006.

[17] A. T. Pavia, "Viral infections of the lower respiratory tract: old viruses, new viruses, and the role of diagnosis," Clinical Infectious Diseases, vol. 52, supplement 4, pp. S284-S289, 2011.

[18] W. B. Martin, "Respiratory diseases induced in small ruminants by viruses and mycoplasma," Revue Scientifique et Technique des Office International des Epizooties, vol. 2, no. 2, pp. 311-334, 1983.

[19] H. Fred, H. Gill, and M. Powell, Foot Rot in Sheep, Extension ASB-300, University of Tennessee, Knoxville, Tenn, USA, 2008.

[20] K. Dhama, M. Y. Wani, R. Tiwari, and D. Kumar, "Molecular diagnosis of animal diseases: the current trends and perspectives," Livestock Sphere, vol. 1, no. 5, pp. 6-10, 2012. 
[21] K. Dhama, K. Karthik, S. Chakraborty et al., "Loop-mediated isothermal amplification of DNA, (LAMP)-a new diagnostic tool lights the world of diagnosis of animal and human pathogens: a review," Pakistan Journal of Biological Sciences, vol. 17, no. 2, pp. 51-166, 2014.

[22] K. Dhama, S. Chakraborty, S. Kapoor et al., "One world, one health-veterinary perspectives," Advances in Animal and Veterinary Sciences, vol. 1, no. 1, pp. 5-13, 2013.

[23] K. Dhama, A. K. Verma, R. Tiwari et al., "A perspective on applications of geographical information system (GIS), an advanced tracking tool for disease surveillance and monitoring in veterinary epidemiology," Advances in Animal and Veterinary Sciences, vol. 1, no. 1, pp. 14-24, 2013.

[24] R. Deb, S. Chakraborty, B. M. Veeregowda, A. K. Verma, R. Tiwari, and K. Dhama, "Monoclonal antibody and its use in the diagnosis of livestock diseases," Advances in Bioscience and Biotechnology, vol. 4, pp. 62-66, 2013.

[25] M. Munir, S. Zohari, and M. Berg, "Current advances in molecular diagnosis and vaccines for Peste des Petits Ruminants," Springer Briefs Animal Science, vol. 2013, pp. 105-133, 2013.

[26] M. Kumar, V. P. Singh, N. C. Srivastava et al., "Rapid and specific detection of M. Mycoides cluster and differentiation of mycoides group from capricolum group by PCR," Indian Journal of Comparative Microbiology Immunology and Infectious Diseases, vol. 22, no. 2, pp. 118-121, 2001.

[27] P. Saravanan, R. P. Singh, V. Balamurugan et al., "Development of a N gene-based PCR-ELISA for detection of Peste-des-petitsruminants virus in clinical samples," Acta Virologica, vol. 48, no. 4, pp. 249-255, 2004.

[28] B. Schmitt and L. Henderson, "Diagnostic tools for animal diseases," OIE Revue Scientifique et Technique, vol. 24, no. 1, pp. 243-250, 2005.

[29] V. Balamurugan, A. Sen, P. Saravanan et al., "One-step multiplex RT-PCR assay for the detection of Peste des petits ruminants virus in clinical samples," Veterinary Research Communications, vol. 30, no. 6, pp. 655-666, 2006.

[30] V. Balamurugan, A. Sen, G. Venkatesan et al., "A rapid and sensitive one step-SYBR green based semi quantitative real time RT-PCR for the detection of peste des petits ruminants virus in the clinical samples," Virologica Sinica, vol. 27, no. 1, pp. 1-9, 2012.

[31] S. Belák, "Molecular diagnosis of viral diseases, present trends and future aspects. A view from the OIE Collaborating Centre for the Application of Polymerase Chain Reaction Methods for Diagnosis of Viral Diseases in Veterinary Medicine," Vaccine, vol. 25, no. 30, pp. 5444-5452, 2007.

[32] L. Li, J. Bao, X. Wu et al., "Rapid detection of peste des petits ruminants virus by a reverse transcription loop-mediated isothermal amplification assay," Journal of Virological Methods, vol. 170, no. 1-2, pp. 37-41, 2010.

[33] Y. Li, F. Zhou, X. Li, J. Wang, X. Zhao, and J. Huang, "Development of TaqMan-based qPCR method for detection of caprine arthritis-encephalitis virus (CAEV) infection," Archives of Virology, vol. 158, no. 10, pp. 2135-2141, 2013.

[34] C. A. Batten, A. C. Banyard, D. P. King et al., "A real time RT-PCR assay for the specific detection of Peste des petits ruminants virus," Journal of Virological Methods, vol. 171, no. 2, pp. 401-404, 2011.

[35] R. Deb and S. Chakraborty, "Trends in veterinary diagnostics," Journal of Veterinary. Science and Technology, vol. 3, Article ID e103, 2012.
[36] S. Mahajan, R. Agrawal, M. Kumar, A. Mohan, and N. Pande, "Comparative evaluation of RT-PCR with sandwich-ELISA for detection of Peste des petits ruminant in sheep and goats," Veterinary World, vol. 6, no. 6, pp. 288-290, 2013.

[37] T. Abera, A. Thangavelu, N. D. Joy Chandran, and A. Raja, "A SYBR Green I based real-time RT-PCR assay for specific detection of Peste des petits ruminants virus," BMC Veterinary Research, vol. 10, p. 22, 2014.

[38] P. B. Rossiter and W. P. Taylor, "Peste des petits ruminants," in Infectious Diseases of Livestock, Coetzer, Thomson, and Tustin, Eds., vol. 2, pp. 758-765, Oxford University Press, Cape Town, South Africa.

[39] R. P. Singh, P. Saravanan, B. P. Sreenivasa, R. K. Singh, and S. K. Bandyopadhyay, "Prevalence and distribution of peste des petits ruminants virus infection in small ruminants in India," OIE Revue Scientifique et Technique, vol. 23, no. 3, pp. 807-819, 2004.

[40] T. Fentahun and M. Woldie, "Review on Peste Des Petits Ruminants (PPR)," European Journal of Applied Sciences, vol. 4, no. 4, pp. 160-167, 2012.

[41] N. A. Osman, M. E. A Rahman, A. S. Ali, and M. A. Fadol, "Rapid detection of Peste des Petits Ruminants (PPR) virus antigen in Sudan by agar gel precipitation (AGPT) and haemagglutination (HA) Tests," Tropical Animal Health and Production, vol. 40, no. 5, pp. 363-368, 2008.

[42] B. P. Sreenivasa, R. P. Singh, B. Mondal, P. Dhar, and S. K. Bandyopadhyay, "Marmoset B95a cells: a sensitive system for cultivation of peste des petits ruminants (PPR) virus," Veterinary Research Communications, vol. 30, no. 1, pp. 103-108, 2006.

[43] R. C. Dadas, D. Muthuchelvan, A. B. Pandey et al., "Development of loop-mediated isothermal amplification (LAMP) assay for rapid detection of peste des petits ruminants virus (PPRV) genome from clinical samples," Indian Journal of Comparative Microbiology, Immunology and Infectious Diseases, vol. 33, pp. 7-13, 2012.

[44] T. M. Vishwaradhya, P. Minakshi, K. Ranjan, A. Supriya, P. Kumar, and G. Prasad, "Sensitive detection of novel Indian isolate of BTV 21 using ns1 gene based real-time PCR assay," Veterinary World, vol. 6, no. 8, pp. 554-557, 2013.

[45] N. S. Maan, S. Maan, K. Nomikou et al., "The genome sequence of bluetongue virus type 2 from India: evidence for reassortment between eastern and western topotype field strains," Journal of Virology, vol. 86, no. 10, pp. 5967-5968, 2012.

[46] N. S. Maan, S. Maan, M. Guimera et al., "Complete genome sequence of an isolate of bluetongue virus serotype 2, demonstrating circulation of a Western Topotype in Southern India," Journal of Virology, vol. 86, no. 9, pp. 5404-5405, 2012.

[47] N. S. Maan, S. Maan, M. Guimera et al., "The genome sequence of a reassortant bluetongue virus serotype 3 from India," Journal of Virology, vol. 86, no. 11, pp. 6375-6376, 2012.

[48] N. S. Maan, N. S. Maan, M. Guimera et al., "Genome sequence of a reassortant strain of bluetongue virus serotype 23 from western India," Journal of Virology, vol. 86, no. 12, pp. 7011-7012, 2012.

[49] M. Prasad, K. Ranjan, P. Kumar, and G. Prasad, "A novel method of staining of RNA in polyacrylamide gel electrophoresis," Advances in Animal and Veterinary Sciences, vol. 1, supplement 4, pp. 20-23, 2013.

[50] K. Ranjan, G. Prasad, P. Kumar, and M. Prasad, "Molecular characterization of segment 6 of bluetongue serotype 16 of sheep 
origin from India," Advances in Animal and Veterinary Sciences, vol. 2, no. 2, pp. 98-103, 2014.

[51] K. Ranjan, M. Prasad, P. Kumar, and G. Prasad, "VP5 gene based molecular comparison of Indian and global isolates of bluetongue virus 2," Advances in Animal and Veterinary Sciences, vol. 2, no. 2, pp. 91-97, 2014.

[52] P. Kumar, P. Minakshi, K. Ranjan, R. Dalal, and G. Prasad, "Evidence of reassortment between eastern and western topotype strains of bluetongue virus serotype 16 (BTV-16) from India," Advances in Animal and Veterinary Sciences, vol. 1, supplement 4, pp. 14-19, 2013.

[53] A. I. Dadawala, S. K. Biswas, W. Rehman et al., "Isolation of bluetongue virus serotype 1 from Culicoides vector captured in livestock farms and sequence analysis of the viral genome segment-2," Transboundary and Emerging Diseases, vol. 59, no. 4, pp. 361-368, 2012.

[54] A. I. Dadawala, H. S. Kher, B. S. Chandel et al., "Isolation and molecular characterization of bluetongue virus 16 of goat origin from India," Advances in Animal and Veterinary Sciences, vol. 1, supplement 4, pp. 24-29, 2013.

[55] D. J. Johnson, P. P. C. Mertens, and S. Maan, "American Association of Veterinary Laboratory Diagnosticians (AAVLD) disease reporting system," in Proceedings of the Annual Conference of American Association of Veterinary Laboratory Diagnosticians (AAVLD '07), vol. 118, 2007.

[56] P. Fernández-Pacheco, J. Fernández-Pinero, M. Agüero, and M. A. Jiménez-Clavero, "Bluetongue virus serotype 1 in wild mouflons in Spain," Veterinary Record, vol. 162, no. 20, pp. 659$660,2008$.

[57] C. Saegerman, D. Berkvens, and P. S. Mellor, "Bluetongue epidemiology in the European Union," Emerging Infectious Diseases, vol. 14, no. 4, pp. 539-544, 2008.

[58] K. Ranjan, G. Prasad, P. Kumar, and M. Prasad, "Vp5 gene based molecular characterization of bluetongue virus 9 from South India," Advances in Animal and Veterinary Sciences, vol. 1, supplement 4, pp. 30-36, 2013.

[59] I. Julkunen, "Serological diagnosis of Parainfluenza virus infections by enzyme immunoassay with special emphasis on purity of viral antigens," Journal of Medical Virology, vol. 14, no. 2, pp. 177-187, 1984.

[60] S. S. Maidana, P. M. Lomonaco, G. Combessies et al., "Isolation and characterization of bovine Parainfluenza virus type 3 from water buffaloes (Bubalus bubalis) in Argentina," BMC Veterinary Research, vol. 8, p. 83, 2012.

[61] R. Rosadio, E. Cirilo, A. Manchego, and H. Rivera, "Respiratory syncytial and parainfluenza type 3 viruses coexisting with Pasteurella multocida and Mannheimia hemolytica in acute pneumonias of neonatal alpacas," Small Ruminant Research, vol. 97, no. 1-3, pp. 110-116, 2011.

[62] M. Lyon, C. Leroux, T. Greenland, J. Chastang, J. Patet, and J.F. Mornex, "Presence of a unique parainfluenza virus 3 strain identified by RT-PCR in visna-maedi virus infected sheep," Veterinary Microbiology, vol. 57, supplement 2-3, pp. 95-104, 1997.

[63] P. F. Horwood, J. L. Gravel, and T. J. Mahony, "Identification of two distinct bovine parainfluenza virus type 3 genotypes," Journal of General Virology, vol. 89, no. 7, pp. 1643-1648, 2008.

[64] C. Osiowy, "Direct detection of respiratory syncytial virus, parainfluenza virus, and adenovirus in clinical respiratory specimens by a multiplex reverse transcription-PCR assay," Journal of Clinical Microbiology, vol. 36, no. 11, pp. 3149-3154, 1998.
[65] S. Hibbitts, A. Rahman, R. John, D. Westmoreland, and J. D. Fox, "Development and evaluation of NucliSens@ Basic Kit NASBA for diagnosis of parainfluenza virus infection with "end-point" and "real-time" detection," Journal of Virological Methods, vol. 108, no. 2, pp. 145-155, 2003.

[66] A. M. Elfahal, A. M. Zakia, and A. M. El-Hussien, "First report of caprine arthritis encephalitis virus infection hi Sudan," Journal of Animal and Veterinary Advances, vol. 9, no. 4, pp. 736-740, 2010.

[67] J. D. Rowe, N. E. East, M. C. Thurmond, C. E. Franti, and N. C. Pedersen, "Cohort study of natural transmission and two methods for control of caprine arthritis-encephalitis virus infection in goats on a California dairy," American Journal of Veterinary Research, vol. 53, no. 12, pp. 2386-2395, 1992.

[68] P. G. Reddy, W. J. Sapp, and W. Heneine, "Detection of caprine arthritis-encephalitis virus by polymerase chain reaction," Journal of Clinical Microbiology, vol. 31, no. 11, pp. 3042-3043, 1993.

[69] C. Shah, J. B. Huder, J. Böni et al., "Direct evidence for natural transmission of small-ruminant lentiviruses of subtype A4 from goats to sheep and vice versa," Journal of Virology, vol. 78, no. 14, pp. 7518-7522, 2004.

[70] C. A. Shah, J. B. Huder, J. Böni et al., "Direct evidence for natural transmission of small-ruminant lentiviruses of subtype A4 from goats to sheep and vice versa," Journal of Virology, vol. 78, no. 14, pp. 7518-7522, 2004.

[71] C. Shah, J. Böni, J. B. Huder et al., "Phylogenetic analysis and reclassification of caprine and ovine lentiviruses based on 104 new isolates: evidence for regular sheep-to-goat transmission and worldwide propagation through livestock trade," Virology, vol. 319, no. 1, pp. 12-26, 2004.

[72] R. Varea, E. Monleón, C. Pacheco et al., "Early detection of maedi-visna (ovine progressive pneumonia) virus seroconversion in field sheep samples," Journal of Veterinary Diagnostic Investigation, vol. 13, no. 4, pp. 301-307, 2001.

[73] L. M. Herrmann, W. P. Cheevers, K. L. Marshall et al., "Detection of serum antibodies to ovine progressive pneumonia virus in sheep by using a caprine arthritis-encephalitis virus competitive-inhibition enzyme-linked immunosorbent assay," Clinical and Diagnostic Laboratory Immunology, vol. 10, no. 5, pp. 862-865, 2003.

[74] S. J. Brodie, A. De La Concha-Bermejillo, G. D. Snowder, and J. C. DeMartini, "Current concepts in the epizootiology, diagnosis, and economic importance of ovine progressive pneumonia in North America: a review," Small Ruminant Research, vol. 27, no. 1, pp. 1-17, 1998.

[75] L. M. Herrmann-Hoesing, S. N. White, G. S. Lewis, M. R. Mousel, and D. P. Knowles, "Development and validation of an ovine progressive pneumonia virus quantitative PCR," Clinical and Vaccine Immunology, vol. 14, no. 10, pp. 1274-1278, 2007.

[76] L. M. Herrmann-Hoesing, S. M. Noh, K. R. Snekvik et al., "Ovine progressive pneumonia virus capsid antigen as found in CD163- and CD172a-positive alveolar macrophages of persistently infected sheep," Veterinary Pathology, vol. 47, no. 3, pp. 518-528, 2010.

[77] D. L. Yu, N. M. Linnerth-Petrik, C. L. Halbert, S. R. Walsh, and S. K. Wootton, "Jaagsiekte sheep retrovirus and enzootic nasal tumor virus promoters drive gene expression in all airway epithelial cells of mice but only induce tumors in the alveolar region of the lungs," Journal of Virology, vol. 85, no. 15, pp. 7535$7545,2011$. 
[78] J. M. Sharp and J. C. Demartini, "Natural history of JSRV in sheep," Current Topics in Microbiology and Immunology, vol. 275, pp. 55-79, 2002.

[79] F. I. Lewis, F. Brülisauer, C. Cousens, I. J. McKendrick, and G. J. Gunn, "Diagnostic accuracy of PCR for Jaagsiekte sheep retrovirus using field data from 125 Scottish sheep flocks," Veterinary Journal, vol. 187, no. 1, pp. 104-108, 2011.

[80] Y. Kane, S. Rosati, O. M. Diop et al., "Tissue targets and phylogenetic characteristic of the enzootic nasal tumour virus (ENTV) infecting sahelian sheep," Revue de Medecine Veterinaire, vol. 156, no. 1, pp. 29-36, 2005.

[81] K. Zhang, H. Kong, Y. Liu, Y. Shang, B. Wu, and X. Liu, "Diagnosis and phylogenetic analysis of ovine pulmonary adenocarcinoma in China," Virus Genes, vol. 48, no. 1, pp. 64-73, 2014.

[82] C. Cousens, E. Minguijon, R. G. Dalziel et al., "Complete sequence of enzootic nasal tumor virus, a retrovirus associated with transmissible intranasal tumors of sheep," Journal of Virology, vol. 73, no. 5, pp. 3986-3993, 1999.

[83] P. Nagavelli, An investigation into the serological and molecular diagnosis of Jaagsiekte sheep retrovirus (JSRV) [Ph.D. thesis], (M.Med.)-University of KwaZulu-Natal, Durban, South Africa, 2005.

[84] J. Storz, X. Lin, C. W. Purdy et al., "Coronavirus and Pasteurella infections in bovine shipping fever pneumonia and Evans'criteria for causation," Journal of Clinical Microbiology, vol. 38, no. 9, pp. 3291-3298, 2000.

[85] C. Brown, "Hemorrhagic septicemia," in Foreign Animal Diseases, pp. 297-300, United States Animal Health Association, Boca Raton, Fla, USA, 2008.

[86] R. F. Montgomerie, "Enzootic pneumonia in sheep," Journal of Comparative Pathology and Therapeutics, vol. 51, pp. 87-107, 1938.

[87] J. Orós, A. Fernández, J. L. Rodríguez, F. Rodríguez, and J. B. Poveda, "Bacteria associated with enzootic Pneumonia in goats," Journal of Veterinary Medicine B, vol. 44, no. 2, pp. 99104, 1997.

[88] P. C. Verma and S. A. Kamil, "Clinico-haematological studies on Pasteurella multocida infection in layers," Indian Journal of Animal Sciences, vol. 75, no. 4, pp. 422-424, 2005.

[89] P. C. Verma, "Different vaccines against a local fowl cholera isolate-a comparison," Indian Journal of Animal Sciences, vol. 75, no. 2, pp. 199-202, 2005.

[90] G. C. Chaturvedi and Minakshi, "Immunodiagnostics for diagnosis of Pasteurella infection in livestock and poultry," in Laboratory Manual on Recent Approaches in Immunodiagnostics for Livestock and Poultry Diseases, pp. 43-45, 2000.

[91] Minakshi, G. C. Chaturvedi, P. Sarthi, and P. Tomar, "Detection of P. multocida antibody in the serum of cattle by dot immunobinding assay and Rose Bengal test," in Laboratory Manual on Recent Approaches in Immunodiagnostics for Livestock and Poultry Diseases, pp. 114-116, 2000.

[92] P. Tomer, G. C. Chaturvedi, A. Minakshi, P. Malik, and D. P. Monga, "Comparative analysis of the outer membrane protein profiles of isolates of the Pasteurella multocida (B:2) associated with haemorrhagic septicaemia," Veterinary Research Communications, vol. 26, no. 7, pp. 513-522, 2002.

[93] World Organization for Animal Health (OIE), World Animal Health Information Database (WAHID) [Database Online]List of Countries By Sanitary Situation: Haemorrhagic Septicemia, World Organization for Animal Health (OIE), Paris, France,
2009, http://www.oie.int/wahis/public.php?page=disease_status_lists.

[94] S. K. Brickell, L. M. Thomas, K. A. Long, M. Panaccio, and P. R. Widders, "Development of a PCB test based on a gene region associated with the pathogenicity of pasteurella multocida serotype B:2, the causal agent of Haemorrhagic Septicaemia in Asia," Veterinary Microbiology, vol. 59, no. 4, pp. 295-307, 1998.

[95] A. A. Kumar, P. C. Harbola, R. B. Rimler, and P. N. Kumar, "Studies on Pasteurella multocida isolates of animal and avian origin from India," Indian Journal of Comparative Microbiology Immunology and Infectious Diseases, vol. 17, pp. 120-124, 1996.

[96] B. A. Hopkins, T. H. M. Huang, and L. D. Olson, "Differentiating turkey postvaccination isolants of Pasteurella multocida using arbitrarily primed polymerase chain reaction," Avian Diseases, vol. 42, no. 2, pp. 265-274, 1998.

[97] M. C. Smith, "Exclusion of infectious diseases from sheep and goat farms," The Veterinary Clinics of North America. Food Animal Practice, vol. 6, no. 3, pp. 705-720, 1990.

[98] M. D. Piontkowski and D. W. Shivvers, "Evaluation of a commercially available vaccine against Corynebacterium pseudotuberculosis for use in sheep," Journal of the American Veterinary Medical Association, vol. 212, no. 11, pp. 1765-1768, 1998.

[99] Z. Ilhan, "Detection of Corynebacterium pseudotuberculosis from sheep lymph nodes by PCR," Revue de Medecine Veterinaire, vol. 164, no. 2, pp. 60-66, 2013.

[100] E. A. ter Laak, J. Bosch, G. C. Bijl, and B. E. Schreuder, "Doubleantibody sandwich enzyme-linked immunosorbent assay and immunoblot analysis used for control of caseous lymphadenitis in goats and sheep," American Journal of Veterinary Research, vol. 53, no. 7, pp. 1125-1132, 1992.

[101] D. P. Dercksen, J. M. A. Brinkhof, T. Dekker-Nooren et al., "A comparison of four serological tests for the diagnosis of caseous lymphadenitis in sheep and goats," Veterinary Microbiology, vol. 75, no. 2, pp. 167-175, 2000.

[102] M. F. Rebouças, R. W. Portela, D. D. Lima et al., "Corynebacterium pseudotuberculosis secreted antigen-induced specific gamma-interferon production by peripheral blood leukocytes: potential diagnostic marker for caseous lymphadenitis in sheep and goats," Journal of Veterinary Diagnostic Investigation, vol. 23, no. 2, pp. 213-220, 2011.

[103] B. Çetinkaya, M. Karahan, E. Atil, R. Kalin, T. De Baere, and M. Vaneechoutte, "Identification of Corynebacterium pseudotuberculosis isolates from sheep and goats by PCR," Veterinary Microbiology, vol. 88, no. 1, pp. 75-83, 2002.

[104] A. J. DaMassa, P. S. Wakenell, and D. L. Brooks, "Mycoplasmas of goats and sheep," Journal of Veterinary Diagnostic Investigation, vol. 4, no. 1, pp. 101-113, 1992.

[105] R. A. J. Nicholas, "Improvements in the diagnosis and control of diseases of small ruminants caused by mycoplasmas," Small Ruminant Research, vol. 45, no. 2, pp. 145-149, 2002.

[106] W. Al-Momani, M. N. Abo-Shehada, and R. A. J. Nicholas, "Seroprevalence of and risk factors for Mycoplasma mycoides subspecies capri infection in small ruminants in Northern Jordan," Tropical Animal Health and Production, vol. 43, no. 2, pp. 463-469, 2011.

[107] P. Kumar, A. Roy, B. B. Bhanderi, and B. C. Pal, "Isolation, identification and molecular characterization of Mycoplasma isolates from goats of Gujarat State, India," Veterinarski Arhiv, vol. 81, no. 4, pp. 443-458, 2011.

[108] A. Kumar, A. K. Verma, and A. Rahal, "Mycoplasma bovis, a multi disease producing pathogen: an overview," Asian Journal 
of Animal and Veterinary Advances, vol. 6, no. 6, pp. 537-546, 2011.

[109] W. Shahzad, R. Munir, M. Y. Rana et al., "Prevalence, molecular diagnosis and treatment of Mycoplasma conjunctivae isolated from infectious keratoconjunctivitis affected Lohi sheep maintained at Livestock Experiment Station, Bahadurnagar, Okara, Pakistan," Tropical Animal Health and Production, vol. 45, no. 3 , pp. 737-742, 2013.

[110] A. Kumar, N. C. Srivastava, and V. P. Singh, "Rapid identification of M. agalactiae and M. bovis by immuno binding assay," Indian Journal of Comparative Microbiology, Immunology and Infectious Diseases, vol. 23, no. 2, pp. 161-163, 2002.

[111] A. Kumar and V. P. Singh, "Characterization of Mycoplasma bovis sonicated supernatant antigens (SSA)," The Indian Veterinary Journal, vol. 88, no. 12, pp. 9-10, 2011.

[112] A. Kumar and V. P. Singh, "Characterization of Mycoplasma agalactiae sonicated supernatant protein antigens (SSA) by Sephadex G-200 column chromatography and SDS-PAGE," The Indian Veterinary Journal, vol. 85, no. 5, pp. 9-10, 2011.

[113] A. Kumar, N. C. Srivastava, and V. P. Singh, "Analysis of Mycoplasma agalactiae and Mycoplasma bovis antigens by Polyacrylamide gel electrophoresis (PAGE)," Indian Journal of Small Ruminants, vol. 16, no. 1, pp. 271-273, 2010.

[114] A. Kumar, N. C. Srivastava, V. P. Singh, and J. Sunder, "SDS-PAGE and immunoblotting analysis based detection of cross reactive immunogenic proteins of Indian isolates of Mycoplasma agalactiae and Mycoplasma bovis," Veterinary Medicine international, 2014.

[115] A. Kumar, N. C. Srivastava, V. P. Singh, and V. P. Singh, "Identification of potential diagnostic and protective antigen for Mycoplasma bovis," Indian Journal of Comparative Microbiology and Infectious Diseases, vol. 34, no. 1, pp. 29-32, 2013.

[116] D. Zendulková, H. J. Ball, A. Madanat, P. Lány, and Z. Pospíšil, "Detection of Mycoplasma agalactiae antigen in sheep and goats by monoclonal antibody- based sandwich ELISA," Acta Veterinaria Brno, vol. 73, no. 4, pp. 461-464, 2004.

[117] U. Sadique, Z. I. Chaudhry, M. Younas et al., "Molecular characterization of contagious caprine pleuropneumonia (CCPP) in small ruminants of Khyber Pakhtunkhwa, Pakistan," The Journal of Animal and Plant Sciences, vol. 22, supplement 2, pp. 33-37, 2012.

[118] M. A. Awan, F. Abbas, M. Yasinzai et al., "Prevalence of Mycoplasma capricolum subspecies capricolum and Mycoplasma putrefaciens in goats in Pishin district of Balochistan," Pakistan Veterinary Journal, vol. 29, no. 4, pp. 179-185, 2009.

[119] C. A. Becker, F. Ramos, E. Sellal, S. Moine, F. Poumarat, and F. Tardy, "Development of a multiplex real-time PCR for contagious agalactia diagnosis in small ruminants," Journal of Microbiological Methods, vol. 90, no. 2, pp. 73-79, 2012.

[120] D. Otranto and J. R. Stevens, "Molecular approaches to the study of myiasis-causing larvae," International Journal for Parasitology, vol. 32, no. 11, pp. 1345-1360, 2002.

[121] M. Alcaide, D. Reina, J. Sánchez-López, E. Frontera, and I. Navarrete, "Seroprevalence of Oestrus ovis (Diptera, Oestridae) infestation and associated risk factors in ovine livestock from southwestern Spain," Journal of Medical Entomology, vol. 42, no. 3, pp. 327-331, 2005.

[122] K. Y. Mumcuoglu and R. Eliashar, "Nasal myiasis due to Oestrus ovis larvae in Israel," The Israel Medical Association Journal, vol. 13, no. 6, pp. 379-380, 2011.

[123] F. Francesconia and O. Lupi, "Myiasis," Clinical Microbiology Reviews, vol. 25, no. 1, pp. 79-105, 2012.
[124] C. R. Bautista-Garfias, R. M. Angulo-Contreras, and E. GarayGarzon, "Serologic diagnosis of Oestrus ovis (Diptera:Oestridae) in naturally infested sheep," Medical and Veterinary Entomology, vol. 2, no. 4, pp. 351-355, 1988.

[125] P. Goddard, P. Bates, and K. A. Webster, "Evaluation of a direct ELISA for the serodiagnosis of Oestrus ovis infections in sheep," The Veterinary record, vol. 144, no. 18, pp. 497-501, 1999.

[126] M. Sekiya, A. Zintl, and M. Doherty, "Bulk milk ELISA and the diagnosis of parasite infections in dairy herds: a review," Irish Veterinary Journal, vol. 66, p. 14, 2013.

[127] S. Azizi, F. S. Korani, and A. Oryan, "Pneumonia in slaughtered sheep in south-western Iran: pathological characteristics and aerobic bacterial aetiology," Veterinaria Italiana, vol. 49, no. 1 , pp. 109-118, 2013.

[128] J. B. Weiss, "DNA probes and PCR for diagnosis of parasitic infections," Clinical Microbiology Reviews, vol. 8, no. 1, pp. 113130, 1995.

[129] K. A. Goodwin, R. Jackson, C. Brown, P. R. Davies, R. S. Morris, and N. R. Perkins, "Pneumonic lesions in lambs in New Zealand: patterns of prevalence and effects on production," New Zealand Veterinary Journal, vol. 52, no. 4, pp. 175-179, 2004.

[130] N. B. Chilton, "The use of nuclear ribosomal DNA markers for the identification of bursate nematodes (order Strongylida) and for the diagnosis of infections," Animal Health Research Reviews, vol. 5, no. 2, pp. 173-187, 2004.

[131] H. C. Chauhan, B. S. Chandel, H. N. Kher, A. I. Dadawala, and S. M. Agrawal, "Peste des petits ruminants virus infection in animals," Veterinary World, vol. 2, no. 4, pp. 150-155, 2009.

[132] Food and Agricultural Organization, "Deadly animal virus Peste des petits ruminants threatens to spread to Southern Africa," Goal Geology, 2011, animal virus peste-des-petitsruminants-threatens-to-spread-to-southern-africa/8302.

[133] K. S. Choi, J. J. Nah, Y. J. Ko, S. Y. Kang, K. J. Yoon, and N. I. Jo, "Antigenic and immunogenic investigation of B-cell epitopes in the nucleocapsid protein of peste des petits ruminants virus," Clinical and Diagnostic Laboratory Immunology, vol. 12, no. 1, pp. 114-121, 2005.

[134] S. N. Sapre, "An outbreak of bluetongue in goats and sheep," Indian Veterinary Review, vol. 15, pp. 78-80, 1964.

[135] P. K. Uppal and B. Vasudevan, "Occurrence of bluetongue in India," Indian Journal of Comparative Microbiology Immunology Infectious Diseases, vol. 1, pp. 18-20, 1980.

[136] G. Prasad, D. Sreenivasulu, K. P. Singh, P. P. C. Mertens, and S. Maan, "Bluetongue in the Indian subcontinent," in Bluetongue, P. Mellor, M. Baylis, and P. C. Merten, Eds., pp. 167-195, Elsevier, London, UK, 2009.

[137] R. Jensen and B. L. Swift, Diseases of Sheep, Lea and Febiger, Philadelphia, Pa, USA, 1982.

[138] M. Prasad, K. Ranjan, A. Bhateja, M. Shafiq, A. Kumar, and G. Prasad, "Detection of multiple genetic variants of BTV serotype-1 originated from different geographical regions in India," Indian Journal of Field Veterinarian, vol. 7, no. 2, pp. 6368, 2011.

[139] Y. Malik, S. Maan, and G. Prasad, "Comparison of cultural characteristics and genomic profiles of two strains of bluetongue virus 1 of Indian origin," Indian Journal of Animal Sciences, vol. 70, no. 1, pp. 3-7, 2000.

[140] P. Minakshi, R. Singh, K. Ranjan et al., "Complete genome sequence of bluetongue virus serotype 16 of Goat Origin from India," Journal of Virology, vol. 86, no. 15, pp. 8337-8339, 2012. 
[141] T. B. Crawford, D. S. Adams, W. P. Cheevers, and L. C. Cork, "Chronic arthritis in goats caused by a retrovirus," Science, vol. 207, no. 4434, pp. 997-999, 1980.

[142] M. Pépin, C. Vitu, P. Russo, J. Mornex, and E. Peterhans, "Maedi-visna virus infection in sheep: a review," Veterinary Research, vol. 29, no. 3-4, pp. 341-367, 1998.

[143] R. C. Cutlip, H. D. Lehmkuhl, J. M. Sacks, and A. L. Weaver, "Seroprevalence of ovine progressive pneumonia virus in sheep in the United States as assessed by analyses of voluntarily submitted samples," American Journal of Veterinary Research, vol. 53, no. 6, pp. 976-979, 1992.

[144] A. de la Concha-Bermejillo, "Maedi-Visna and ovine progressive pneumonia," The Veterinary Clinics of North America. Food Animal Practice, vol. 13, no. 1, pp. 13-33, 1997.

[145] A. P. Galvani and R. M. May, "Epidemiology: dimensions of superspreading," Nature, vol. 438, no. 7066, pp. 293-295, 2005.

[146] D. F. York, R. Vigne, D. W. Verwoerd, and G. Querat, "Nucleotide sequence of the jaagsiekte retrovirus, an exogenous and endogenous type D and B retrovirus of sheep and goats," Journal of Virology, vol. 66, no. 8, pp. 4930-4939, 1992.

[147] G. Vitellozzi, L. Mughetti, M. Palmarini et al., "Enzootic intranasal tumour of goats in Italy," Journal of Veterinary Medicine B, vol. 40, no. 7, pp. 459-468, 1993.

[148] M. N. Alloui, J. Kaba, and N. Alloui, "Prevalence and risk factors of caseous lymphadenitis in sheep and goats of Batna area (Algeria)," Research Opinions in Animal and Veterinary Sciences, vol. 1, no. 1, pp. 62-164, 2011.

[149] D. M. West, A. N. Bruere, and A. L. Ridler, "Caseous Lymphadenitis," in The Sheep: Health, Disease, \& Production, pp. 274-279, Foundation for Continuing Education, Palmerston North, New Zealand, 2nd edition, 2002.

[150] D. C. Ruffin, "Mycoplasma infections in small ruminants," The Veterinary Clinics of North America. Food Animal Practice, vol. 17, no. 2, pp. 315-332, 2001.

[151] A. Kumar, N. C. Srivastava, and V. P. Singh, "Antigenic characterization of Mycoplasma agalactiae by SDS-PAGE and Immunoblotting," Research Journal of Microbiology, vol. 9, no. 1, pp. 59-65, 2014.

[152] O. O. Ikpeze, "Diagnosis of nasal myiasis in the West African dwarf (WAD) sheep at Umudike, Abia state, South-Western Nigeria," Animal Research International, vol. 6, no. 1, 2009.

[153] T. Bekele, T. Woldeab, A. Lahlou-Kassi, and J. Sherington, "Factors affecting morbidity and mortality on-farm and onstation in the Ethiopian highland sheep," Acta Tropica, vol. 52, no. 2-3, pp. 99-109, 1992.

[154] A. Ozkara, "The effect of Haemophilys ovis on bronchopneumonic cases of sheep and lambs," Pendik-Veteriner-Mikrobiyoloji-Derjisi, vol. 29, pp. 31-49, 1998.

[155] G. O. Egwu, J. A. Ameh, M. M. Aliyu, and F. D. Mohammed, "Caprine mycoplasmal mastitis in Nigeria," Small Ruminant Research, vol. 39, no. 1, pp. 87-91, 2001.

[156] F. Poumarat, D. Le Grand, and D. Bergonier, "Propriétés générales des mycoplasmes et hypervariabilité antigénique," Point Veterinary, vol. 28, pp. 761-767, 1996. 

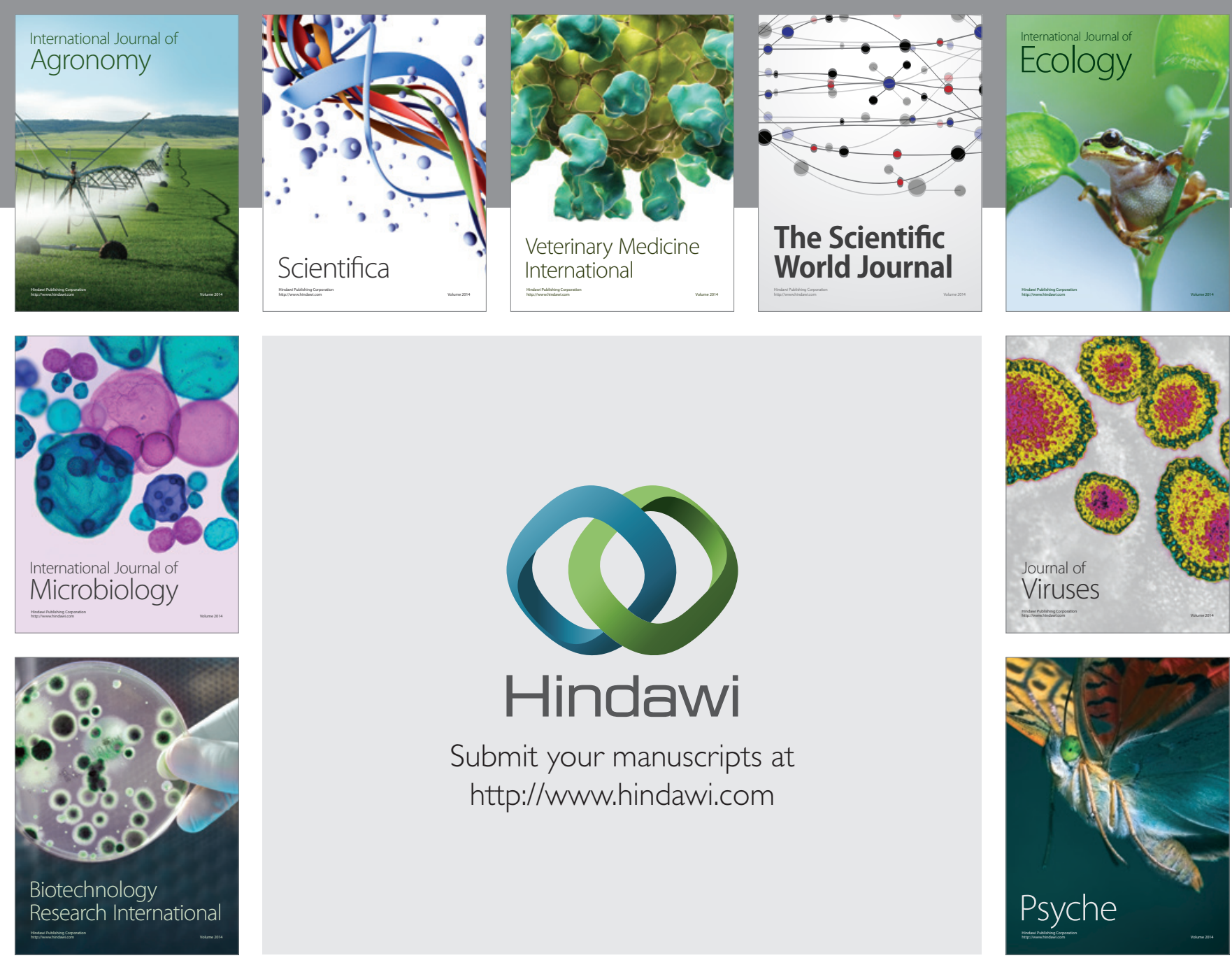

Submit your manuscripts at http://www.hindawi.com
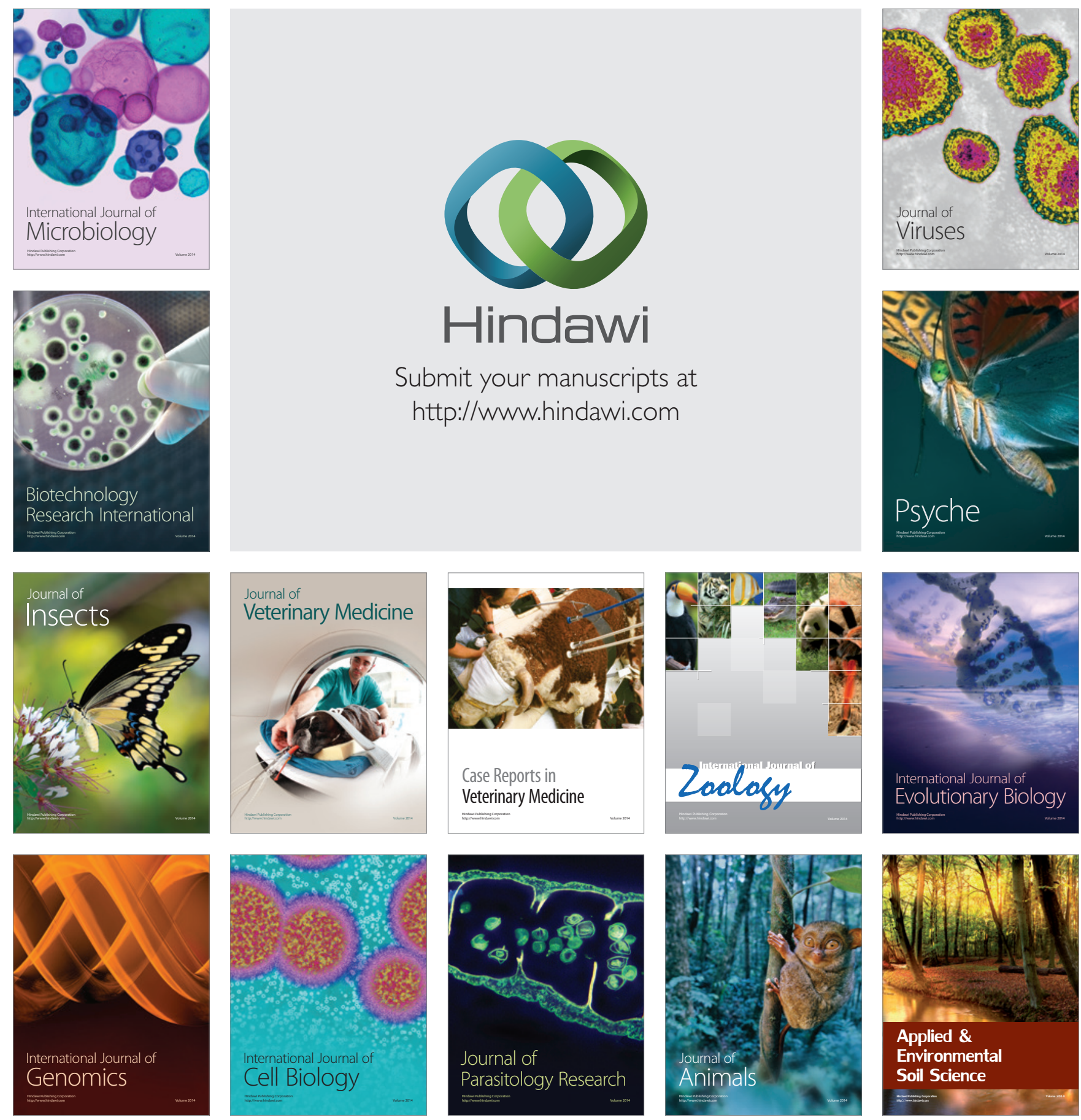